\title{
INCIDÊNCIA DE MICRORGANISMOS CONTAMINANTES EM POLPAS DE FRUTAS COMERCIALIZADAS IN NATURA EM FEIRAS LIVRES DA CIDADE DE SÃO LUÍS/MA
}

\author{
ADENILDE RIBEIRO NASCIMENTO* \\ JOÃO ELIAS MOUCHREK FILHO* \\ SILVIO CARVALHO MARINHO** \\ ANDRÉ GUSTAVO LIMA DE ALMEIDA MARTINS*** \\ MARTHA REIS SOUSA**** \\ WALDENIA ASCENÇÃO SOUSA DA SILVA**** \\ FRANCISCAAMAYA CASTILLO***** \\ MARLUCY BEZERRA OLIVEIRA*****
}

\begin{abstract}
O objetivo deste trabalho foi avaliar as condições higiênico-sanitárias de diversos tipos de polpas de frutas comercializadas nas feiras livres de São Luís-MA, Brasil. Realizaram-se as análises de coliformes a $45^{\circ} \mathrm{C}$, Salmonella sp., Staphylococcus coagulase positiva e bolores e leveduras em 40 amostras adquiridas em feiras livres. Os resultados mostraram ausência de Salmonella sp. e Staphylococcus coagulase positiva nas alíquotas das amostras, respectivamente, $25 \mathrm{~mL}$ e $0,1 \mathrm{~mL}$. Porém, verificou-se $100 \%$ de contaminação por bolores e leveduras e $12 \%$ por coliformes a $45^{\circ} \mathrm{C}$. Algumas cepas de enterobactérias patogênicas ao homem foram identificadas, dentre as quais Escherichia coli, Enterobacter aerogenes, Klebsiella pneumoniae, Citrobacter freundii, Erwinia uredovora e Proteus mirabilis.
\end{abstract}

PALAVRAS-CHAVE: POLPAS DE FRUTAS; COLIFORMES; Salmonella sp.; Staphylococcus COAGULASE POSITIVA; ENTEROBACTÉRIAS.

* Professores do Departamento de Tecnologia Química, Pavilhão Tecnológico, Universidade Federal do Maranhão (UFMA), São Luís, MA, Brasil (e-mail: adenild@bol.com.br, mouchrek@ufma.br).

** Doutorando em Química Analítica, Universidade Federal da Paraíba (UFPB).

*** Doutorando em Ciência e Tecnologia de Alimentos, UFPB.

**** Especialista em Tecnologia de Alimentos, UFMA, São Luis, MA.

***** Químicas Industriais, UFMA, São Luis, MA

***** Graduanda em Química Industrial, UFMA, São Luis, MA. 


\section{INTRODUÇÃO}

As frutas são utilizadas como matéria-prima para a elaboração de diferentes produtos alimentícios, dentre os quais sucos, refrescos, geléias, sorvetes e doces (SANTOS et al., 2004). Dessa forma, a produção de polpas de frutas congeladas tornou-se meio favorável para o aproveitamento integral das frutas na época da safra evitando os problemas ligados à sazonalidade (BARRET, CHITARRA e CHITARRA, 1994).

Segundo o Ministério da Agricultura, Pecuária e Abastecimento, a polpa de fruta pode ser definida como "produto não-fermentado, nãoconcentrado, não-diluído, obtido pelo esmagamento de frutas polposas mediante processo tecnológico adequado, com teor mínimo de sólidos totais provenientes da parte comestível do fruto (BRASIL, 2000).

BUENO et al. (2002) relatam que o número de indústrias de polpas de frutas tem aumentado por que o produto apresenta características de praticidade, sendo adquirido não só pelas donas de casa, mas também por hotéis, restaurantes, lanchonetes e até hospitais.

A qualidade das frutas constitui fator essencial no processamento das polpas, as quais devem ser sãs, limpas, isentas de matéria terrosa, de parasitas e de detritos de animais ou vegetais. Não podem conter fragmentos das partes não-comestíveis da fruta, nem substâncias estranhas, observando-se também a ausência de sujidades, parasitas e larvas (SANTOS et al., 2004). A importância desses cuidados é fundamental, principalmente pelo aumento dos relatos sobre surtos de infecções humanas associados com o consumo de frutas in natura, vegetais e sucos de frutas não-pasteurizados (BEAN et al., 1997; PARISH, 1997).

As bactérias, os bolores e as leveduras deteriorantes fazem parte da microbiota dominante das frutas e dos vegetais. Dentre as espécies de bactérias patogênicas encontradas nesses alimentos estão Shigella sp., Salmonella sp., Escherichia coli patôgenica e Clostridium botulinum produtor de toxina. A contaminação ocorre, principalmente, durante o cultivo, colheita, manipulação, processamento, distribuição e armazenamento (BEUCHAT, 1996). 
No intuito de avaliar as condições higiênico-sanitárias das polpas de frutas comercializadas nas feiras livres de São Luís do Maranhão, a presente pesquisa objetivou analisar microbiologicamente diversos tipos de polpas regionais que podem se tornar veículos de toxinfecções.

\section{MATERIAL E MÉTODOS}

Coletaram-se no período de julho a setembro de 2004, 40 amostras de polpas de frutas de sabores distintos comercializadas por vendedores em feiras livres da cidade de São Luís-MA. As amostras foram acondicionadas em caixas isotérmicas e transportadas ao Laboratório de Microbiologia do Programa de Controle de Qualidade de Alimentos e Água da Universidade Federal do Maranhão (PCQA-UFMA) para a realização das análises pertinentes.

Alíquotas de $25 \mathrm{~mL}$ de cada amostra foram pipetadas, assepticamente, e transferidas para frascos erlenmeyer, contendo $225 \mathrm{~mL}$ de solução salina estéril a $0,85 \%$ - diluição $10^{-1}$. A partir dessa diluição foram efetuadas as diluições decimais seriadas até $10^{-5}$.

Na determinação do Número Mais Provável (NMP/mL) de coliformes a 45C utilizou-se a técnica dos tubos múltiplos e Caldo EC. Após a inoculação, os tubos foram incubados em banho-maria por 24 horas. Efetuou-se o cálculo do Número Mais Provável $(\mathrm{NMP} / \mathrm{mL})$ de coliformes a 45ํㅡ com o auxílio da Tabela de Hoskins (APHA, 2001).

Procedeu-se a identificação das espécies da família Enterobacteriaceae a partir dos tubos positivos do Caldo EC. Realizou-se o plaqueamento nos meios de cultura Ágar Eosina Azul de Metileno e Agar MacConkey, sendo os tubos incubados a $37^{\circ} \mathrm{C}$. Logo após, as colônias foram transferidas para tubos inclinados contendo Ágar Triptona de Soja (Ágar TSA) para serem submetidas aos seguintes testes bioquímicos: indol, vermelho de metila, Voges-Proskauer, citrato de Simmons, caldo malonato, caldo uréia, sacarose, lactose, manitol, inositol, glicose, rafinose, lisina, ornitina e arginina (APHA, 2001).

Para a pesquisa de Salmonella sp. foram homogeneizados $25 \mathrm{~mL}$ de 
cada polpa reconstituída em $225 \mathrm{~mL}$ de água peptonada tamponada. Após incubação a 35ㄷ por 24 horas, alíquotas de $1 \mathrm{~mL}$ e $0,1 \mathrm{~mL}$ dessa suspensão foram transferidas para $10 \mathrm{~mL}$ de Caldo Tetrationato e Rappaport, respectivamente, com incubação a 35ํ․ Em seguida, semeaduras por esgotamento foram efetuadas em placas de Petri contendo Ágar Rambach e Hektoen. As colônias suspeitas foram isoladas em Ágar TSA e após o período de incubação a 35ํㅡ por 24 horas submetidas aos testes bioquímicos (APHA, 2001).

Na pesquisa de Staphylococcus coagulase positiva inoculou-se $0,1 \mathrm{~mL}$ de cada diluição na superfície de placas de Petri, contendo Ágar Baird Parker. Em seguida incubaram-se as placas a $35^{\circ} \mathrm{C}$ por 48 horas. Logo após, as colônias suspeitas foram transferidas para Ágar TSA, incubadas a $35^{\circ} \mathrm{C}$ por 24 horas e realizados os testes de coagulase (APHA, 2001).

Para a contagem de bolores e leveduras pipetou-se assepticamente $1 \mathrm{~mL}$ de cada diluição, distribuindo-as em placas contendo Ágar batata dextrose acidificado a $10 \%$ de ácido tartárico. Em seguida incubaramse as placas a $25^{\circ} \mathrm{C}$ por cinco dias. As unidades formadoras de colônias foram calculadas de acordo com as diluições (APHA, 2001).

\section{RESULTADOS E DISCUSSÃO}

$\mathrm{Na}$ Tabela 1 constam os resultados obtidos nas análises microbiológicas das 40 amostras de polpas de frutas.

Não foi detectada contaminação por Salmonella sp. ou Staphylococcus coagulase positiva em nenhuma das amostras analisadas, respeitadas as alíquotas das amostras indicadas em Material e Métodos. No teste para coliformes a $45^{\circ} \mathrm{C}, 35$ das 40 amostras enquadraram nos padrões microbiológicos estabelecidos pela Resolução $n^{\circ}=12$, de 02 de janeiro de 2001 (ANVISA, 2001).

A quantificação de bolores e leveduras evidenciou $100 \%$ de contaminação das amostras, variando entre $1,0 \times 10^{5} \mathrm{e} 1,1 \times 10^{8}$, mas a legislação brasileira não estabelece padrões para esses microrganismos (ANVISA, 2001). 
TABELA 1 - DISTRIBUIÇÃO DO NÚMERO MAIS PROVÁVEL DE COLIFORMES A 45ㄷ (NMP/g), PESQUISA DE Salmonella sp., PESQUISA DE Staphylococcus COAGULASE POSITIVA E CONTAGEM DE BOLORES E LEVEDURAS (UFC/mL)

\begin{tabular}{|c|c|c|c|c|}
\hline Amostras & $\begin{array}{c}\text { Coliformes a 45ㄷ } \\
(\mathrm{NMP} / \mathrm{mL})\end{array}$ & $\begin{array}{l}\text { Salmonella sp. } \\
\text { em } 25 \text { mL }\end{array}$ & $\begin{array}{c}\text { Staphylococcus } \\
\text { coagulase positiva } \\
\text { em } 0,1 \mathrm{~mL}\end{array}$ & $\begin{array}{l}\text { Bolores e } \\
\text { leveduras } \\
\text { (UFC/mL) }\end{array}$ \\
\hline $\begin{array}{c}1 \\
2 \\
3 \\
4 \\
5 \\
6 \\
7 \\
8 \\
9 \\
10 \\
\end{array}$ & $\begin{array}{l}23 \\
<3 \\
<3 \\
<3 \\
<3 \\
<3 \\
43 \\
20 \\
<3 \\
<3\end{array}$ & $\begin{array}{l}\text { Ausência } \\
\text { Ausência } \\
\text { Ausência } \\
\text { Ausência } \\
\text { Ausência } \\
\text { Ausência } \\
\text { Ausência } \\
\text { Ausência } \\
\text { Ausência } \\
\text { Ausência }\end{array}$ & $\begin{array}{l}\text { Ausência } \\
\text { Ausência } \\
\text { Ausência } \\
\text { Ausência } \\
\text { Ausência } \\
\text { Ausência } \\
\text { Ausência } \\
\text { Ausência } \\
\text { Ausência } \\
\text { Ausência }\end{array}$ & $\begin{array}{l}3,6 \times 10^{6} \\
1,1 \times 10^{6} \\
3,2 \times 10^{6} \\
1,8 \times 10^{5} \\
3,7 \times 10^{5} \\
1,0 \times 10^{5} \\
2,6 \times 10^{5} \\
6,6 \times 10^{5} \\
1,2 \times 10^{5} \\
1,5 \times 10^{5}\end{array}$ \\
\hline $\begin{array}{l}11 \\
12 \\
13 \\
14 \\
15 \\
16 \\
17 \\
18 \\
19 \\
20 \\
\end{array}$ & $\begin{array}{c}<3 \\
15 \\
<3 \\
<3 \\
<3 \\
4 \\
<3 \\
<3 \\
<3 \\
<3\end{array}$ & $\begin{array}{l}\text { Ausência } \\
\text { Ausência } \\
\text { Ausência } \\
\text { Ausência } \\
\text { Ausência } \\
\text { Ausência } \\
\text { Ausência } \\
\text { Ausência } \\
\text { Ausência } \\
\text { Ausência }\end{array}$ & $\begin{array}{l}\text { Ausência } \\
\text { Ausência } \\
\text { Ausência } \\
\text { Ausência } \\
\text { Ausência } \\
\text { Ausência } \\
\text { Ausência } \\
\text { Ausência } \\
\text { Ausência } \\
\text { Ausência }\end{array}$ & $\begin{array}{l}2,4 \times 10^{7} \\
3,2 \times 10^{7} \\
3,2 \times 10^{7} \\
2,5 \times 10^{7} \\
1,5 \times 10^{7} \\
4,0 \times 10^{7} \\
1,3 \times 10^{7} \\
4,8 \times 10^{6} \\
2,9 \times 10^{7} \\
9,0 \times 10^{6}\end{array}$ \\
\hline $\begin{array}{l}21 \\
22 \\
23 \\
24 \\
25 \\
26 \\
27 \\
28 \\
29 \\
30\end{array}$ & $\begin{array}{c}240 \\
7 \\
<3 \\
- \\
<3 \\
<3 \\
7 \\
<3 \\
<3 \\
<3\end{array}$ & $\begin{array}{l}\text { Ausência } \\
\text { Ausência } \\
\text { Ausência } \\
\text { Ausência } \\
\text { Ausência } \\
\text { Ausência } \\
\text { Ausência } \\
\text { Ausência } \\
\text { Ausência } \\
\text { Ausência }\end{array}$ & $\begin{array}{l}\text { Ausência } \\
\text { Ausência } \\
\text { Ausência } \\
\text { Ausência } \\
\text { Ausência } \\
\text { Ausência } \\
\text { Ausência } \\
\text { Ausência } \\
\text { Ausência } \\
\text { Ausência }\end{array}$ & $\begin{array}{c}2,2 \times 10^{7} \\
5,0 \times 10^{4} \\
3,2 \times 10^{6} \\
1,0 \times 10^{4} \\
- \\
5,8 \times 10^{5} \\
1,3 \times 10^{5} \\
1,8 \times 10^{5} \\
4,5 \times 10^{7} \\
1,5 \times 10^{7}\end{array}$ \\
\hline $\begin{array}{l}31 \\
32 \\
33 \\
34 \\
35 \\
36 \\
37 \\
38 \\
39 \\
40 \\
\end{array}$ & $\begin{array}{c}280 \\
2400 \\
21 \\
28 \\
75 \\
210 \\
210 \\
15 \\
28 \\
<3 \\
\end{array}$ & $\begin{array}{l}\text { Ausência } \\
\text { Ausência } \\
\text { Ausência } \\
\text { Ausência } \\
\text { Ausência } \\
\text { Ausência } \\
\text { Ausência } \\
\text { Ausência } \\
\text { Ausência } \\
\text { Ausência }\end{array}$ & $\begin{array}{l}\text { Ausência } \\
\text { Ausência } \\
\text { Ausência } \\
\text { Ausência } \\
\text { Ausência } \\
\text { Ausência } \\
\text { Ausência } \\
\text { Ausência } \\
\text { Ausência } \\
\text { Ausência }\end{array}$ & $\begin{array}{l}1,5 \times 10^{8} \\
1,7 \times 10^{8} \\
6,6 \times 10^{7} \\
5,1 \times 10^{7} \\
9,6 \times 10^{7} \\
1,1 \times 10^{8} \\
3,5 \times 10^{7} \\
2,7 \times 10^{7} \\
2,2 \times 10^{8} \\
2,0 \times 10^{8}\end{array}$ \\
\hline Padrão* & $100 \mathrm{NMP} / \mathrm{g}$ & Ausência em $25 \mathrm{~g}$ & - & - \\
\hline
\end{tabular}

*Estabelecido pela ANVISA (2001). 
Pesquisadores como LEITE et al. (2000), NASCIMENTO et al. (1999) e FEITOSA et al. (1997) estudaram bolores e leveduras em polpas de frutas e todos encontraram altas contagens.

Os resultados verificados no presente trabalho podem representar forte indício de contaminação da matéria-prima, ou condições de armazenamento inadequadas. Segundo FRANCO E LANDGRAF (1996), a presença desses microrganismos nos alimentos pode representar perigo à saúde pública em razão da produção de micotoxinas pelos bolores.

A presença de bactérias do grupo coliformes a $45^{\circ} \mathrm{C}$, especialmente Escherichia coli, indica provável contaminação dos alimentos com material de origem fecal (FLORENTINO, 1997). Essa contaminação pode estar associada à qualidade da água utilizada no processo, ou com práticas inadequadas de higiene pessoal dos manipuladores (PELCZAR, 1996). Além da importância desses microrganismos como indicadores da contaminação fecal, alguns podem ser responsáveis por diversas doenças como a Escherichia coli $\mathrm{O}_{157}: \mathrm{H}_{7}$, considerada grande problema para questões de saúde pública em diversos países (TRABULSI, 1998; BOYCE, SWERDLOW e GRIFFIN, 1998). Essas cepas de Escherichia coli patogênica de origem alimentar foram caracterizadas a partir de 1971, embora haja evidências de sua associação com diarréias infantis no século XVIII (JAY, 2000).

Os resultados obtidos corroboram os de SANTOS e MARTINS (1999) que não verificaram a presença de Salmonella em 43 amostras de polpas congeladas de diferentes frutos comercializados em Petrolina/ PE. No entanto, esses autores constataram contaminação por coliformes.

Identificaram-se espécies de bactérias da família Enterobacteriaceae (Tabela 2) nas amostras das polpas de frutas analisadas. Esses resultados são preocupantes pelo fato das polpas serem utilizadas, basicamente, para a elaboração de sucos e néctares, consumidos sem nenhum tratamento térmico que possa reduzir o número de microrganismos contaminantes. 
TABELA 2 - DISTRIBUIÇÃO DAS ESPÉCIES DE BACTÉRIAS DA FAMÍLIA ENTEROBACTERIACEAE IDENTIFICADAS NAS AMOSTRAS DE POLPA DE FRUTAS COMERCIALIZADAS EM FEIRAS LIVRES DA CIDADE DE SÃO LUÍS-MA

\begin{tabular}{l|c|c}
\hline \multicolumn{1}{c|}{ Gêneros isolados } & Espécies identificadas & Quantidade (\%) \\
\hline \multirow{2}{*}{ Escherichia } & coli & 24,0 \\
& vulneris & 1,1 \\
\cline { 2 - 3 } Enterobacter & blattae & 7,1 \\
& aerogenes & 9,5 \\
& asburiae & 2,3 \\
\hline Klebsiella & amngenus & 9,5 \\
\hline \multirow{2}{*}{ Citrobacter } & pneumoniae & 5,0 \\
\hline \multirow{2}{*}{ Edwardsiella } & diversus & 8,3 \\
\hline \multirow{2}{*}{ Ewirnia } & freundii & 1,1 \\
\hline \multirow{2}{*}{ Proteus } & sp. & 7,1 \\
& uredovora & 8,3 \\
& amylovora & 1,1 \\
\hline
\end{tabular}

\section{CONCLUSÃO}

As análises realizadas nas polpas de frutas mostraram resultados adequados em relação à ausência de Salmonella sp. e de Staphylococcus coagulase positiva. Quanto à colimetria, $12 \%$ das amostras não se enquadraram nos padrões microbiológicos exigidos pela legislação em vigor, apresentando diversas enterobactérias. Outro grande risco refere-se às altas contagens de bolores e leveduras, sendo que $100 \%$ das amostras apresentaram contaminação com contagens suficientes para a produção de micotoxinas. Entretanto, é preciso identificar as cepas produtoras de micotoxinas e considerar as características intrínsecas do produto para avaliar as condições de sua produção.

A comercialização das polpas de frutas nas feiras livres de São Luís/ MA denuncia falta de conhecimentos básicos dos vendedores no que 
diz respeito à conservação, armazenamento e manipulação do produto, favorecendo a proliferação de inúmeros microrganismos, principalmente os do grupo dos coliformes.

\begin{abstract}
INCIDENCE OF MICROORGANISMS THAT CAN CONTAMINATE FRUIT PULP SOLD IN NATURA IN POPULAR FREE MARKETS OF THE CITY OF SÃO LUÍSMA (BRAZIL)

The aim of this work was to evaluate the sanitary condition of different kinds of fruits pulps merchandized in the popular free markets of the city of São Luís-MA, Brazil. Analysis of the following bacteria were performed: coliforms at $45^{\circ} \mathrm{C}$, Salmonella sp., Staphylococcus positive coagulase, as well as the presence of moulds and yeast in 40 pulp samples purchased at the cited markets. Results showed the absence of Salmonella sp. and Staphylococcus positive coagulase. Nevertheless $100 \%$ were contaminated by moulds and yeast and $12 \%$ contaminated by coliforms at $45^{\circ} \mathrm{C}$. Some strains of human pathogenic enterobacteria were identified, such as Escherichia coli, Enterobacter aerogenes, Klebsiella pneumoniae, Citrobacter freundii, Erwinia uredovora and Proteus mirabilis.
\end{abstract}

KEY-WORDS: FRUIT-PULP; COLIFORMS; Salmonella sp.; Staphylococcus POSITIVE COAGULASE; ENTEROBACTERIA.

\title{
REFERÊNCIAS
}

1 APHA. American Public Health Association. Compendium of methods for the microbiological of foods. $4^{\text {th }}$ ed. Washington, 2001.

2 ANVISA. Agência Nacional de Vigilância Sanitária. Resolução no 12 de 02 de janeiro de 2001. Aprova o regulamento técnico sobre padrões microbiológicos para alimentos. Diário Oficial [da] República Federativa do Brasil, Brasília, 10 de janeiro de 2001. n.7, seção 1, p. 45-53.

3 BARRET, R.L.C.; CHITARRA, M.I.F.;CHITARRA, A.B. Choque a frio e atmosfera modificada no aumento da vida pós-colheita de tomates: coloração e textura. Ciência e Tecnologia de Alimentos, Campinas, v. 1, n. 14, p. 14-26, 1994.

4 BEAN, N.H.; GOULDING, J.S; DANIELS, M.T.; ANGELO F.J. Surveillance for foodborne disease outbreaks-United States, 1988-1992. Journal of Food Protection, v. 60, p. 1265-1286, 1997. 
5 BEUCHAT, L. R. Pathogenic microorganisms associated to fresh produce. Journal of Food Protection, v. 59, p. 204-216, 1996.

6 BOYCE, T.G.; SWERDLOW, D.L.; GRIFFIN, P.M. Escherichia coli $\mathrm{O}_{157}: \mathrm{H}_{7}$ and the hemolytic uremic syndrome. The New England Journal of Medicine, v.333, p. 364-368, 1995.

7 BRASIL. Ministério da Agricultura, Pecuária e Abastecimento. Instrução Normativa n. 01, de 7 de janeiro de 2000. Aprova padrões de identidade e qualidade para polpas de frutas. Diário Oficial [da] República Federativa do Brasil, Brasília, 10 janeiro de 2000 , seção 1, p. 54.

8 BUENO, S.M.; LOPES, M.R.V.; GRACIANO, R.A.S.; FERNANDES, E.C.B.; GARCIA-CRUZ, C.H. Avaliação da qualidade de polpas de frutas congeladas. Revista do Instituto Adolfo Lutz, São Paulo, v.62, n.2, p. 121-126, 2002.

9 FEITOSA, T.; BASTOS, M.S.R.; OLIVEIRA, M.E.B.; MUNIZ, C.R. Perfil microbiológico de polpas de frutas produzidas e comercializadas nos Estados do Ceará e Rio Grande do Norte. Boletim do CEPPA, Curitiba, v.15, n. 1, p. 65-74, jan/jun. 1997.

10 FLORENTINO, E.R.; LEITE JUNIOR, A.F.; SÁ, S.N.;ARAÚJO, M. S. O.; MARTINS, R.S. Avaliação da qualidade microbiológica da carne moída comercializada em Campina Grande-PB. Revista Higiene Alimentar, São Paulo, v. 11, n. 47, p.38-41, jan/fev, 1997.

11 FRANCO, B.D.G.M.; LANDGRAF, M. Microbiologia de alimentos. São Paulo: Atheneu, 1996.

12 JAY, J.M. Modern food microbiology. $6^{\text {th }}$ ed. Maryland: Aspen, 2000.

13 LEITE, C.C.; SANTANA, L.R.R.; SILVA, M.D.; SANT'ANNA, M.E.B.; ASSIS, P.N. Avaliação microbiológica de polpas congeladas de frutas produzidas no Estado da Bahia. Revista Higiene Alimentar, São Paulo, v.14, n. 78/79, p.69-79, nov./dez. 2000.

14 NASCIMENTO, A.R.; MOUCHREK FILHO, V.E; MOUCHREK FILHO, J.E.; CANTANHEDE, F.B. Perfil microbiológico das polpas de acerola (Malpighia glabra) e abacaxi (Ananas comosus), produzidas e comercializadas na llha de São Luís/MA. Revista Higiene Alimentar, São Paulo, v. 13, n. 62, p. 44-47, jun. 1999. 
15 PARISH, M.E. Public health and nonpasteurized fruit juices. Crit. Rev. Microbiol., v. 23, p. 109-119, 1997.

16 PELCZAR, M.J. Microbiologia. São Paulo: McGraw-Hill, 1996.

17 SANTOS, F.A.; SALLES, J.R.J.; CHAGAS FILHO, E.; RABELO, R.N. Análise qualitativa de polpas congeladas de frutas, produzidas pelo SUFRUTS, MA. Revista Higiene Alimentar, São Paulo, v.15, n. 119, p.14-22, abr. 2004.

18 SANTOS, I.A.; MARTINS, S.S. Avaliação microbiológica de polpas de frutas tropicais congeladas fabricadas e comercializadas em Petrolina-PE. In: CONGRESSO BRASILEIRO DE MICROBIOLOGIA, 1999, Salvador-BA. Anais... Salvador: Sociedade Brasileira de Microbiologia, 1999. v.1. p.52.

19 TRABULSI, L.C.; CAMPOS, L.C.; RODRIGUES, S.J.; GONÇALVES, A.G. Traditional and non traditional enteropathogenic Escherichia coli serogroups. Revista de Microbiologia, São Paulo, n. 27, supl. 1, p.1-6, 1998. 